\title{
Хромосомная изменчивость в поколениях ЭМС-мутантных линий ярового рапса
}

Амосова А.В. ${ }^{{ }^{*},}$, к.б.н, с.н.с.; Земцова Л.В. ${ }^{l}$, ст. лаб.; Зощук С.А. ${ }^{l}$, к.б.н, н.с.; Гуськова Н.И. ${ }^{2}$, студент; Юркевич О.Ю. ${ }^{l}$, к.б.н, н.с.; Саматадзе Т.Е. ${ }^{l}$, к.б.н, н.с.; Муравенко О.В. ${ }^{1}$, д.б.н., г.н.с.

${ }^{I}$ ФГБУН Институт молекулярной биологии им. В.А. Энгельгардта РАН, Москва, Российская Федерачия;

${ }^{2}$ Московский государственный университет им. М.В. Ломоносова, Москва, Российская Федерация.

e-mail:amomar@mail.ru

Впервые изучены ичитогенетическая изменчивость растений хозяйственно-ценных мутантных линий рапсового и сурепичного морфотипов, выделенных в поколениях ярового рапса канола сорта Викрос после обработки ЭМС. Сравнительный анализ структуры кариотипов и хромосомного распределения локусов $45 S$ and $5 S$ рДНК у растений исходного сорта и мутантных форм показал относительную стабильность их геномов. В некоторых линиях М3-Мб обнаружены полиморфные варианты хромосом, а также гомеологическое межгеномное замещение, ди- и трисомия. Наши результаты подтвердили эффективность использования низких концентраиий ЭМС в селекции рапса, а выделенные мутантные линии рапсового и сурепичного морфотипов перспективны для получения новых хозяйственноценных сортов.

Ключевые слова: Brassica napus L., ЭМС мутагенез, кариотип, FISH.

\section{Chromosomal variability in generations of spring rapeseed ems mutant lines}

Amosova A.V. ${ }^{\text {, }, Z e m t s o v a ~ L . V . ~}{ }^{1}$, Zoshchuk S.A. ${ }^{\text {}, ~ G u s k o v a ~ N . I . ~}{ }^{2}$, Yurkevich O.Yu. ${ }^{1}$, Samatadze T.E. ${ }^{l}$, Muravenko O.V. ${ }^{1}$

${ }^{1}$ Engelhardt Institute of Molecular Biology, Russian Academy of Sciences, Moscow, Russian Federation E-mail: amomar@mail.ru

${ }^{2}$ Lomonosov Moscow State University, Moscow, Russian Federation

For the first time, the cytogenetic variability was examined in M2-M6 generations of EMS mutagenized rape seed populations of B. napus- and B. rapa-type generated from canola B. napus cv. Vikros. The comparative analysis of karyotype structure and also FISH-based chromosomal localization of $45 S$ and $5 S$ rDNA between B. napus cv. Vikros and both mutant lines demonstrated relative stability of their genomes. In several M3-M6 lines, polymorphic chromosome variants including homeologous inter-genomic substitutions, di-and trisomy were also re- 
vealed. Our findings confirmed the effectiveness of EMS treatment at low concentrations in rapeseed breeding that resulted in development of two valuable mutant lines important for development of rapeseed varieties with desired characteristics.

Key words: Brassica napus L., EMS mutagenesis, karyotype, FISH.

Рапс (Brassica napus L., 2n=38, геном AACC) является хозяйственноценной культурой многоцелевого применения. Для повышения генетического разнообразия рапса и получения новых высокопродуктивных и устойчивых сортов применяются различные методы, в том числе, химический мутагенез. Например, с помощью химического мутагенеза были получены низкоэруковые, высокоолеиновые, низколиноленовые и устойчивые к заболеваниям сорта рапса [1]. Вместе с тем, использование мутагенеза в процессе селекции может приводить к нарушению геномного гомеостаза и возникновению различных хромосомных и геномных изменений, приводящих к генетической нестабильности потомства. Большая часть исследований мутантных форм рапса, проводится по изучению аллельного полиморфизма и картированию мутантных генов, кодирующих хозяйственно-ценные признаки [2]. В настоящей работе впервые проведен анализ хромосомной изменчивости растений в М2-М6 поколений мутантных форм, выделенных после обработки этилметансульфонатом семян ярового рапса канола сорта Викрос.

Объекты и методы. Материалом для исследования послужили растения ярового рапса канола сорта Викрос, полученные из ФГБНУ ФНЦ кормопроизводства и агроэкологии им. В.Р. Вильямса (г. Москва, Россия). В результате обработки семян $0,2 \%$ раствором этилметансульфоната (ЭМС) и последующего отбора потомства по хозяйственно-ценным признакам в поколениях M2-М6 были получены мутантных форм рапсового и сурепичного морфотипов. Приготовление хромосомных препаратов, процедуру FISH c зондами $45 \mathrm{~S}$ и $5 \mathrm{~S}$ рДНК, а также анализ хромосом проводили по разработанным нами ранее методикам [3].

Результаты и обсуждение. Рапс является природным амфидиплоидом, геном которого включает А- и С-субгеномы. Поэтому этот вид представляет собой важную модель для изучения процессов геномного взаимодействия и реорганизации, происходящих в сложных геномах недавно возникших полиплоидов. Примерами такого взаимодействия служат выявленные в кариотипе рапса различные хромосомные перестройки и межгеномные замещения, возникающие, вероятно, для поддержания геномной стабильности $[4,5]$. Ранее нами показано, что под давлением искусственного отбора по определенным признакам в поколениях ресинтезантов рапса наблюдались анеуплоидные формы, различные хромосомные аберрации, потеря отдельных хромосом и даже целого субгенома, что коррелировало с фенотипической изменчивостью этих гибридов [6]. Для исследования хромо- 
сомной изменчивости мы провели сравнительный анализ структуры кариотипов исходного сорта Викрос и растений в М2-М6 поколениях обеих мутантных популяций. Обнаружено, что у большинства изученных мутантных растений рапсового типа структура кариотипов, в основном, не отличалось от исходного сорта Викрос. FISH анализ подтвердил сходство кариотипов растений этой популяции с исходным сортом по хромосомному распределению сайтов $45 \mathrm{~S}$ и $5 \mathrm{~S}$ рДНК (3 пары хромосом с отдельным локусом $45 \mathrm{~S}$ рДНК, две пары хромосом с отдельными локусами 5S рДНК и 4 пары хромосом с ко-локализованными кластерами 45S и 5S рДНК). В некоторых линиях M3-M6 обнаружены полиморфные варианты хромосом 9Ас дополнительным сигналом 5S рДНК и гетероморфизм гомологов 4А по наличию кластеров рДНК. У большинства изученных мутантных растений сурепичного типа структура кариотипов также не отличалось от исходного сорта Викрос, но выявлен полиморфизм по локализации $45 \mathrm{~S}$ и $5 \mathrm{~S}$ рДНК на хромосомах Асубгенома. Полиморфизм по числу и хромосомному распределению локусов $45 \mathrm{~S}$ и $5 \mathrm{~S}$ рдНК наблюдался и ранее у разных сортов рапса [3]. Вместе с тем, в поколениях M3-M6 в кариотипах ряда растений сурепичного типа выявлены и значительные хромосомные нарушения (гомеологическое межгеномное замещение, дисомия, двойная трисомия). Обнаруженные мутантные растения сурепичного типа с такими структурными хромосомными изменениями могут использоваться для получения форм рапса с трисомией и/или линий с замещением/дополнением хромосом. Такие анеуплоидные линии позволяют получать интрогрессивные линии растений и дают возможность контролировать экспрессию гетерологичных генов и взаимодействие между геномом-реципиентом и хромосомами-донорами у растений [7, 8]. Кроме того, наличие хромосомных аномалий у мутантных растений в разных поколениях указывает на необходимость анализа структуры кариотипов мутантных линий при их передаче на сортоиспытание.

Заключение. Проведенное в настоящей работеисследование хромосомной изменчивости у мутантных растений подтвердило эффективность использования низких концентраций ЭМС в селекции рапса, а выделенные мутантные линии рапсового и сурепичного морфотипов перспективны для получения новых хозяйственно-ценных сортов с нужными свойствами.

Благодарности: Работа выполнена при поддержке РФФИ (проект № 17-29-08034 офи-м), а также в рамках Программы фундаментальных исследований государственных академий наук на 2013-2020 годы (тема № 01201363824$)$.

\section{Список литературы}

1. Spasibionek S. New mutants of winter rapeseed (Brassica napus L.) with changed fatty acid composition // Plant Breeding. 2006. V.125. P. 259-267.

2. Mikolajczyk K., Dabert M., Karlowski W.M., Spasibionek S., Nowakowska J., Cegielska-Taras T., Bartkowiak-Broda I. Allele-specific SNP markers for the low linolenic 
mutant genotype of winter oilseed rape // Plant Breeding. 2010. V. 129. P. 502-507.

3. Amosova A.V., Zemtsova L.V., Grushetskaya Z.E., Samatadze T.E., Mozgova G.V., Pilyuk Y.E., Volovik V.T., Melnikova N.V., Zelenin A.V., Lemesh V.A., Muravenko O.V. Intraspecific chromosomal and genetic polymorphism in Brassica napus L. detected by cytogenetic and molecular markers // Journal of Genetics. 2014. V. 93. P. 133-143.

4. Xiong Z.Y., Gaeta R.T., Pires J.C. Homoeologous shuffling and chromosome compensation maintain genome balance in resynthesized allopolyploid Brassica napus // Proceedings of the National Academy of Sciences USA. 2011. V. 108. P. 7908-7913.

5. Mason A.S., Snowdon R.J. Oilseed rape: learning about ancient and recent polyploid evolution from a recent crop species // Plant Biol (Stuttg). 2016. V. 18. P. 883-892.

6. Amosova A.V., Zemtsova L.V., Yurkevich O.Y., Zhidkova E.N., Książczyk T., Shostak N.G., Muravlev A.A., Artemyeva A.M., Samatadze T.E., Zoshchuk S.A., Muravenko O.V. Genomic changes in generations of synthetic rapeseed-like allopolyploid grown under selection // Euphytica. 2017. V. 213. P. 217-229.

7. Howell P.M, Marshal D.F, Lydiate D.J. Towards developing intervarietal substitution lines in Brassica napus using marker assisted selection // Genome. 1996. V. 39. P. 348358.

8. Barthes L., Ricroch A. Interspecific chromosomal rearrangements in monosomic addition lines of Allium // Genome. 2001. V. 44. P. 929-935.

DOI 10.18699/GPB2020-06

\section{Изучение коллекции пшеницы мягкой яровой для выявления высокоурожайных источников устойчивых к комплексу болезней}

Апарина В.A. ${ }^{l}$ *, магистрантка; Пискарев B.B. ${ }^{2}$, к.с.-х.н., зав. лаб. генофонда растений; Бойко Н.И. ${ }^{2}$, м.н.с.; Сухомлинов В.Ю. ${ }^{2}$, агроном 1 категории.

${ }^{1}$ ФБОУ ВО Новосибирский ГАУ, Новосибирск, Россия;

${ }^{2}$ СибНИИРС - филиал ИЦиГ СО РАН, Новосибирск, Россия

*e-mail: apari-na.viktoriya@yandex.ru

В результате оценки 158 коллекционных линий пиеницьы мягкой яровой в условиях 2019 года выделены образцы устойчивые к одному или нескольким заболеваниям с урожайностью выше или на уровне стандартов. Ранние сорта - Norm $\left(527,7\right.$ 2/ $\left.\mathrm{M}^{2}\right)$ и Kenуоп $(528,6)$; среднеранние и среднеспелье - Этюд (678,9), Свеча (606,2), CDC Merlin (610,5), Легенда $(660,2)$, Лютесиенс 503 (663,9), Харьковская 22 (527,8), PS 133 (568,9), Aletch $(558,1)$, NIL Thatcher Lr36 (469,3), Геракл (579,7), МИС (543,2), Омская 37 (548,5), Glenlea (465,8), AC Drummond (559,5), Cunnigharn (416,8), среднепоздниеМерцана (658,1), Воевода (686,5), Экада $6(545,7)$, Тулайковская $5(604,2)$, WW 17283 (574,1), Маргарита (558,6), Омская 38 (528,4), Nardo (560,3), Tyлайковская 110 (511,9), Тулайковская золотистая (507,3), Тулайковская 108 $(605,9)$, Rh 66-6 (590,5), Тулайковская $10(580,1)$, Экада 85 (593,2). Для подтверждения урожайных качеств линий необходимо продолжить изучение 